\title{
Introducing: The Landmark Series
}

\author{
Kelly M. McMasters, MD, PhD $^{1}$
}

The Hiram C. Polk, Jr. MD Department of Surgery, School of Medicine, University of Louisville, Louisville, KY

Tremendous progress has been made in the treatment of cancer. The oldest treatment modality-surgery-remains the most effective treatment for many types of solid tumors. Advances in surgical techniques, along with improvements in neoadjuvant therapies and perioperative care, have allowed the extirpation of tumors once thought to be inoperable. Newer challenges include further development of minimally invasive approaches and enhanced recovery after surgery. Still, all cancer surgeons understand the limitations of surgery. The field of surgical oncology involves much more than surgery; it is about multidisciplinary care to achieve the best outcomes for our patients. Advances in adjuvant therapies, i.e. radiation therapy, chemotherapy, targeted therapy, and immunotherapy, have improved survival and quality of life for patients with many types of cancer. Many questions remain regarding the optimal combination, timing, and sequence of these various cancer treatment modalities.

While initially slow and plodding, evidence-based progress in the multidisciplinary treatment of cancer has increased dramatically. Many have decried the sometimes painfully slow process of randomized controlled trials to answer key questions and define the best treatment options. To accelerate the pace of progress, some have sought alternative forms of evidence that can substitute for randomized controlled trials, or surrogates for disease-free and overall survival endpoints; however, the gold standard form of evidence for practice-changing advances in cancer treatment remains the randomized controlled trial. The

(C) Society of Surgical Oncology 2019

First Received: 19 August 2019; Published Online: 11 October 2019

K. M. McMasters, MD, PhD

e-mail: mcmasters@louisville.edu long road of progress in cancer research is littered with therapeutic dogma that has been cast aside once subjected to the rigors of properly conducted clinical trials.

It is fundamentally important for all cancer surgeons to understand the progression of evidence that has led to the current treatment recommendations for each type of solid tumor. This includes clinical trials of surgical techniques, as well as adjuvant therapies. While the earliest clinical trials in cancer treatment may now seem like ancient history to some, they are the cornerstones of our specialty. How can one understand current approaches for managing axillary lymph nodes in breast cancer without understanding the National Surgical Adjuvant Breast and Bowel Project (NSABP) B-04 trial? ${ }^{1}$ How can one understand current trials of non-operative management of rectal cancer without understanding the Swedish Rectal Cancer Trial? ${ }^{2}$ How can one appreciate the Multicenter Selective Lymphadenectomy Trial $\mathrm{II}^{3}$ without understanding the results of the Intergroup Melanoma Trial of elective lymph node dissection? ${ }^{4}$ How can one comprehend the potential of adjuvant targeted therapies without studying the American College of Surgeons Oncology Group (ACOSOG) Trial Z9001 of adjuvant imatinib for gastrointestinal stromal tumors? ${ }^{5}$

The Landmark Series is designed to trace the origins of current multidisciplinary therapy for each type of solid tumor, and demonstrate the logical progression of clinical trials and other key evidence. It is meant to be an educational resource, for trainees and practicing cancer specialists alike, in the understanding of evidence-based cancer management. Practice-changing clinical trials and other key evidence that inform our current treatment guidelines will be summarized and reviewed. Expert authors will provide context and commentary to enhance the value to the reader. The first five articles in this ongoing series, focusing on melanoma, have now been published and are available in this issue. ${ }^{6-10}$ Because the pace of 
change in the field of cancer research has snowballed, it is anticipated that this project will never be completed; we plan to update this series regularly.

Many new therapies remain to be developed and tested. One can now catch a glimpse of the future of cancer treatment: of a time when traditional cytotoxic chemotherapy, radiation, and even surgery (to some degree) may become obsolete; of a time of personalized targeted therapy and immunotherapy; or of a time when our most effective cancer therapies are not measured by their maximally tolerated doses.

To know where we are headed, we must know where we have been. The Landmark Series is meant to be a living roadmap of the progress in the fight against cancer. We hope that it will help guide our way and inspire the work that lies ahead.

\section{REFERENCES}

1. Fisher B, Redmond R, Fisher ER, et al. Ten-year results of a randomized clinical trial comparing radical mastectomy and total mastectomy with or without radiation. $N$ Engl $J$ Med. 1985;312:674-81.

2. Swedish Rectal Cancer Trial. Improved survival with preoperative radiotherapy in resectable rectal cancer. $N$ Engl $\mathrm{J}$ Med. 1997;336:980-7.
3. Faries MB, Thompson JF, Cochran AJ, et al. Completion dissection or observation for sentinel-node metastasis in melanoma. N Engl J Med. 2017;376:2211-22.

4. Balch CM, Soong SJ, Bartolucci AA, et al. Efficacy of an elective regional lymph node dissection of 1 to $4 \mathrm{~mm}$ thick melanomas for patients 60 years of age and younger. Ann Surg. 1996;224:255-63.

5. Dematteo RP, Ballman KV, Antonescu CR, et al. Adjuvant imatinib mesylate after resection of localised, primary gastrointestinal stromal tumour: a randomised, double-blind, placebocontrolled trial. Lancet. 2009;373:1097-104

6. Angeles CV, Wong SL, Karakousis G. The Landmark Series: Randomized trials examining surgical margins for cutaneous melanoma. Ann Surg Oncol. (2019). https://doi.org/10.1245/s10 434-019-07866-y.

7. Bello DM, Faries MB. The Landmark Series: MSLT-1, MSLT-2 and DeCOG (Management of Lymph Nodes). Ann Surg Oncol. (2019). https://doi.org/10.1245/s10434-019-07830-w.

8. Lee AY, Berman RS. The Landmark Series: Non-melanoma skin cancers. Ann Surg Oncol. (2019). https://doi.org/10.1245/s10434019-07831-9.

9. Egger ME, Scoggins CR, McMasters KM. The Sunbelt Melanoma Trial. Ann Surg Oncol. (2019). https://doi.org/10.1245/ s10434-019-07828-4.

10. Beasley GM, Zager JS, Thompson JF. The Landmark Series: Regional therapy of recurrent cutaneous melanoma. Ann Surg Oncol. (2019). https://doi.org/10.1245/s10434-019-07760-7.

Publisher's Note Springer Nature remains neutral with regard to jurisdictional claims in published maps and institutional affiliations. 